\title{
Sensitivity of Sclerotinia sclerotiorum to active substances of fungicides
}

\section{Wrażliwość Sclerotinia sclerotiorum na substancje czynne fungicydów}

\author{
Ilona Świerczyńska*, Agnieszka Perek, Katarzyna Pieczul, Ewa Jajor
}

\section{Summary}

The sensitivity of Sclerotinia sclerotiorum isolates to fungicidal active substances was assessed by means of azoxystrobin, boscalid, prochloraz, tebuconazole and thiophanate-methyl at four concentrations. The isolates were inoculated to a medium with an active substance. The percentage of inhibition of colony proliferation was assessed and the term of emergence of sclerotia was observed. Prochloraz and tebuconazole were the active substances which inhibited the proliferation of S. sclerotiorum colonies most. Azoxystrobin was the least effective active substance inhibiting the proliferation of colonies. When the active substances were applied at lower concentrations, i.e. 1, 5 and $10 \mathrm{ppm}$, they only slightly delayed the process of sclerotia emergence, but thiophanate-methyl concentrated at $10 \mathrm{ppm}$ was an exception. Boscalid, prochloraz and thiophanate-methyl added at 25 ppm inhibited the emergence of sclerotia in $45-96.7 \%$ of the isolates under study.

Key words: Sclerotinia sclerotiorum; active substances; sclerotia

\section{Streszczenie}

W badaniach poddano ocenie wrażliwość izolatów Sclerotinia sclerotiorum na substancje czynne fungicydów: azoksystrobinę, boskalid, prochloraz, tebukonazol i tiofanat metylowy użyte w czterech stężeniach. Izolaty wyszczepiano na pożywkę z dodatkiem substancji czynnej i oceniano procent hamowania wzrostu kolonii oraz obserwowano termin pojawienia się sklerocjów. Spośród zastosowanych substancji czynnych najsilniej wzrost kolonii S. sclerotiorum ograniczały prochloraz oraz tebukonazol. Substancją czynną, która w najmniejszym stopniu hamowała wzrost kolonii była azoksystrobina. Zastosowane substancje czynne w niższych stężeniach: 1, 5 i 10 ppm nieznacznie opóźniły proces wytwarzania sklerocjów, z wyjątkiem tiofanatu metylowego w stężeniu 10 ppm. Dodatek boskalidu, prochlorazu i tiofanatu metylowego w dawce 25 ppm doprowadził do całkowitego zahamowania wytwarzania sklerocjów u 45-96,7\% badanych izolatów.

Słowa kluczowe: Sclerotinia sclerotiorum; substancje czynne; sklerocja

\footnotetext{
Instytut Ochrony Roślin - Państwowy Instytut Badawczy

Zakład Mikologii

Władysława Węgorka 20, 60-318 Poznań

*corresponding author: i.swierczynska@iorpib.poznan.pl
} 


\section{Wstęp / Introduction}

Rzepak należy do ważniejszych roślin uprawnych w Polsce. Wzrasta zarówno jego udział w strukturze zasiewów, jak i liczba rolników uprawiających rzepak (Kapusta 2015). Uzyskanie wysokich plonów jest możliwe pod warunkiem prawidłowo prowadzonej agrotechniki, doboru odmian oraz ochrony chemicznej upraw. Ryzyko wystąpienia chorób rzepaku związane jest $\mathrm{z}$ uproszczeniami w płodozmianie oraz uprawą bezorkową (Rudko 2011). Straty plonu nasion spowodowane porażeniem przez grzyby patogeniczne mogą wynosić od kilku do kilkudziesięciu procent (Jędryczka 2006; Korbas i wsp. 2008).

Do najczęściej występujących chorób, o poważnym znaczeniu gospodarczym należy między innymi zgnilizna twardzikowa (Koch i wsp. 2007). Choroba ta powodowana jest przez powszechnie występującego w Polsce patogena - Sclerotinia sclerotiorum (Lib.) de Bary. Grzyb ten jest polifagiem i infekuje ponad 400 gatunków roślin, w tym wiele gatunków roślin uprawnych i ozdobnych (Boland i Hall 1994; Bolton i wsp. 2006). Obecność patogena częściej odnotowuje się w rejonach o dużym udziale rzepaku w strukturze zasiewów (Paul 1988; Korbas i wsp. 2008; Kaczmarek i wsp. 2012). Źródłem infekcji są znajdujące się w glebie formy przetrwalnikowe $S$. sclerotiorum - sklerocja. Do najintensywniejszego porażenia roślin dochodzi w okresie kwitnienia i tuż po kwitnieniu (Starzycki i Starzycka 1999). W tym czasie sklerocja wytwarzają apotecja z przenoszonymi przez wiatr zarodnikami workowymi - askosporami. Straty plonu nasion, wywołane porażeniem plantacji rzepaku przez $S$. sclerotiorum, mogą sięgać do 60\% (Gwiazdowski i Korbas 2005). W tej sytuacji skuteczne ograniczenie występowania zgnilizny twardzikowej w okresie wegetacji jest szczególnie istotne. Większość zarejestrowanych w Polsce fungicydów do ochrony rzepaku wykazuje szeroki zakres działania grzybobójczego. Ich skład opiera się głównie na substancjach czynnych z grup: benzimidazoli, imidazoli, strobiluryn i triazoli.

U grzybów patogenicznych dla roślin coraz częściej odnotowuje się zjawisko odporności na substancje czynne fungicydów. Dotyczy to także populacji $S$. sclerotiorum (Li i wsp. 2006). Przyczyną tego zjawiska mogą być mutacje w genach białek docelowych dla fungicydów lub inne mechanizmy (Ma i Michailides 2005; Deising i wsp. 2008). Na powstawanie odporności grzybów na stosowane fungicydy może mieć wpływ między innymi długotrwałe stosowanie substancji czynnych o zbliżonym mechanizmie działania oraz zaniżanie dawek stosowanych środków grzybobójczych (Ma i Michailides 2005; Deising i wsp. 2008). Z uwagi na ryzyko nabywania przez S. sclerotiorum odporności na substancje czynne wskazana jest stała ocena skuteczności stosowanych fungicydów.

Celem pracy było porównanie skuteczności ograniczania wzrostu izolatów $S$. sclerotiorum przez substancje czynne fungicydów $\mathrm{z}$ różnych grup chemicznych stosowanych w ochronie rzepaku, w warunkach in vitro.

\section{Materiały i metody / Materials and methods}

W badaniach wykorzystano 60 izolatów S. sclerotiorum, w tym 43 izolaty wyizolowane $\mathrm{z}$ różnych odmian rzepaku oraz 17 izolatów z innych gatunków roślin. Izolaty były zbierane w latach 2011-2015 na terenie całej Polski. Wszystkie badane kultury grzybów zostały oznaczone na podstawie cech morfologicznych grzybni. Badania odporności $S$. sclerotiorum przeprowadzono w warunkach laboratoryjnych na pożywce PDA (Potato Dextrose Agar, Difco) zawierającej dodatek czystych substancji czynnych fungicydów w stężeniach: $1,5,10$ i 25 ppm. W doświadczeniu wykorzystano 5 substancji czynnych (Sigma) stosowanych w ochronie rzepaku: azoksystrobina (strobiluryny), boskalid (anilidy), prochloraz (imidazole), tebukonazol (triazole) oraz tiofanat metylowy (benzimidazole). Substancje czynne zostały rozpuszczone w metanolu w stężeniu $5 \mathrm{mg} / \mathrm{ml}$ i następnie dodane do płynnej pożywki PDA. Pożywka została rozlana na szalki Petriego o średnicy $55 \mathrm{~mm}$. Na zestaloną pożywkę przenoszono krążek (wycięty korkoborem o średnicy $3 \mathrm{~mm}$ ) grzybni pobranej z tygodniowych kultur S. sclerotiorum. Kontrolę stanowiły kolonie grzybów rosnące na pożywce PDA bez substancji czynnych. Po 2 dniach inkubacji w temperaturze pokojowej mierzono średnice kolonii grzybów i wyznaczano procent hamowania wzrostu grzybni przez badane substancje czynne w stosunku do wzrostu kolonii kontrolnej rosnącej na samej pożywce PDA (Borecki 1984). Doświadczenie wykonano w dwóch terminach, w dwóch powtórzeniach. Uzyskane wyniki opracowano statystycznie za pomocą analizy wariancji przy użyciu testu Duncana, na poziomie istotności $\alpha=0,05$.

Badane kultury S. sclerotiorum obserwowano przez kolejne 18 dni odnotowując termin formowania sklerocjów oraz analizując wpływ substancji czynnych na opóźnienie tego procesu. Obserwacje prowadzono co drugi dzień od momentu inokulacji notując moment wytworzenia sklerocjów w grzybni.

\section{Wyniki i dyskusja / Results and discussion}

Otrzymane wyniki pozwoliły na ocenę wrażliwości izolatów S. sclerotiorum na wybrane substancje czynne fungicydów stosowanych w ochronie rzepaku przed zgnilizną twardzikową. Wzrost kolonii grzyba zależał istotnie od rodzaju substancji czynnej i jej stężenia. Badania odporności na fungicydy izolatów $S$. sclerotiorum pozwalają na wykrycie szczepów charakteryzujących się brakiem wrażliwości na substancje czynne fungicydów. Wykrycie izolatów o niskiej wrażliwości na substancje czynne dodane do pożywki może wskazywać fungicydy o ograniczonej skuteczności działania wobec S. sclerotiorum (Mueller i wsp. 2002).

Azoksystrobina wprowadzona do pożywki w stężeniu 1 ppm spowodowała zahamowanie wzrostu kolonii $S$. sclerotiorum średnio o 19,8\%. Wyższe stężenie tej substancji czynnej (5 i 10 ppm) spowodowało wzrost skuteczności jej działania w stosunku do badanych izolatów. Przy stężeniu 25 ppm średni procent hamowania wzrostu kolonii wyniósł 53,1\% (tab. 1). Azoksystrobina wykazała również słabe działanie inhibujące wzrost $S$. sclerotiorum w badaniach Gwiazdowskiego i Jajor (2005) oraz Xu i wsp. (2013). Ponadto wyniki otrzymane przez wyżej wymienionych autorów wskazują na większą wrażliwość S. sclerotiorum 
na procymidon niż na azoksystrobinę. Większość badanych izolatów S. sclerotiorum (od 37 do 48) wykazała wrażliwość na azoksystrobinę w zakresach odpowiadających średnim procentom hamowania dla poszczególnych stężeń (tab. 1, 2).

Badane izolaty $S$. sclerotiorum wykazały wysoką wrażliwość na boskalid. Stężenie 1 ppm tej substancji czynnej spowodowało zahamowanie wzrostu izolatów S. sclerotiorum o 40,9\%. Przy stężeniu 5 ppm średni procent hamowania kolonii grzybów wyniósł 55,5\%. Podwyższenie stężenia boskalidu w pożywce spowodowało również wzrost średniego procentu hamowania wzrostu izolatów (10 ppm - 62,0\%, 25 ppm - 69,6\%) (tab. 1). Wyniki otrzymane przez innych badaczy wskazują na dużą wrażliwość izolatów S. sclerotiorum na obecność boska- lidu (Stammler i wsp. 2007; Liu i wsp. 2009; Wang i wsp. 2009). W doświadczeniu Ma i wsp. (2009), boskalid był skuteczniejszy od iprodionu, procymidonu i dimetachloru. Natomiast w doświadczeniu Matherona i Porchasa (2004) boskalid słabiej hamował wzrost grzybni niż fenheksamid, fluazynam, fludioksonil i winklozolina. Większość izolatów S. sclerotiorum (od 38 do 45) mieściła się w zakresach hamowania odpowiadających średnim procentom hamowania wzrostu grzybni przez boskalid w poszczególnych stężeniach (tab. 1,2).

Największą skutecznością w hamowaniu wzrostu kolonii grzybów charakteryzował się prochloraz. Już stężenie 1 ppm tej substancji czynnej spowodowało zahamowanie wzrostu badanych kolonii grzybów o 70,6\%. Zastosowanie

Tabela 1. Średni procent hamowania wzrostu izolatów Sclerotinia sclerotiorum

Table 1. The mean percentage growth inhibition of Sclerotinia sclerotiorum isolates

\begin{tabular}{l|c|c|c|c|c}
\hline \multirow{2}{*}{ Fungicyd - Fungicide } & \multicolumn{2}{|c|}{ Stężenie fungicydu - Concentration of fungicide [ppm] } & \multirow{2}{*}{$\begin{array}{c}\text { Średnia dla fungicydu } \\
\text { Mean for fungicide }\end{array}$} \\
\cline { 2 - 5 } & 1 & 5 & 10 & 25 & \\
\hline Azoxystrobin & $19,8 \mathrm{~b}$ & $29,6 \mathrm{c}$ & $40,6 \mathrm{~d}$ & $53,1 \mathrm{e}$ & $35,8 \mathrm{~A}$ \\
\hline Boscalid & $40,9 \mathrm{~d}$ & $55,5 \mathrm{ef}$ & $62,0 \mathrm{fg}$ & $69,6 \mathrm{gh}$ & $57,0 \mathrm{~B}$ \\
\hline Prochloraz & $70,6 \mathrm{~h}$ & $92,8 \mathrm{ij}$ & $97,4 \mathrm{ij}$ & $99,7 \mathrm{ij}$ & $90,1 \mathrm{E}$ \\
\hline Tebuconazole & $29,8 \mathrm{c}$ & $75,7 \mathrm{~h}$ & $95,8 \mathrm{ij}$ & $100,0 \mathrm{j}$ & $75,3 \mathrm{D}$ \\
\hline Tiophanate-methyl & $7,7 \mathrm{a}$ & $61,3 \mathrm{f}$ & $91,0 \mathrm{i}$ & $98,8 \mathrm{ij}$ & $64,7 \mathrm{C}$ \\
\hline
\end{tabular}

Średnie oznaczone tymi samymi małymi i dużymi literami w obrębie wierszy lub kolumn nie różnią się istotnie przy poziomie $\alpha=0,05$

Mean values marked with the same small and capital letters within a row or column were not statistically significant $\alpha=0.05$

Tabela 2. Liczba izolatów w poszczególnych zakresach hamowania przez substancje czynne fungicydów Table 2. The number of isolates in respective ranges of inhibiting by the active substances of fungicides

\begin{tabular}{|c|c|c|c|c|c|}
\hline \multirow{2}{*}{$\begin{array}{l}\text { Fungicyd } \\
\text { Fungicide }\end{array}$} & \multirow{2}{*}{$\begin{array}{c}\text { Stężenie } \\
\text { Concentration } \\
{[p p m]}\end{array}$} & \multicolumn{4}{|c|}{$\begin{array}{c}\text { Zakres hamowania - Range of inhibiting } \\
{[\%]}\end{array}$} \\
\hline & & $0-25$ & $26-50$ & $51-75$ & $76-100$ \\
\hline \multirow{4}{*}{ Azoxystrobin } & 1 & 41 & 19 & 0 & 0 \\
\hline & 5 & 15 & 44 & 1 & 0 \\
\hline & 10 & 6 & 48 & 6 & 0 \\
\hline & 25 & 2 & 19 & 37 & 2 \\
\hline \multirow{4}{*}{ Boscalid } & 1 & 4 & 44 & 12 & 0 \\
\hline & 5 & 0 & 19 & 38 & 3 \\
\hline & 10 & 0 & 10 & 45 & 5 \\
\hline & 25 & 0 & 2 & 41 & 17 \\
\hline \multirow{4}{*}{ Prochloraz } & 1 & 1 & 1 & 34 & 24 \\
\hline & 5 & 0 & 0 & 1 & 59 \\
\hline & 10 & 0 & 0 & 0 & 60 \\
\hline & 25 & 0 & 0 & 0 & 60 \\
\hline \multirow{4}{*}{ Tebuconazole } & 1 & 18 & 42 & 0 & 0 \\
\hline & 5 & 0 & 2 & 26 & 32 \\
\hline & 10 & 0 & 0 & 2 & 58 \\
\hline & 25 & 0 & 0 & 0 & 60 \\
\hline \multirow{4}{*}{ Tiophanate-methyl } & 1 & 60 & 0 & 0 & 0 \\
\hline & 5 & 14 & 6 & 8 & 32 \\
\hline & 10 & 1 & 2 & 4 & 53 \\
\hline & 25 & 0 & 0 & 0 & 60 \\
\hline
\end{tabular}


wyższych stężeń spowodowało ograniczenie wzrostu izolatów S. sclerotiorum o 92,8\% (5 ppm), 97,4\% (10 ppm) i 99,7\% (25 ppm) (tab. 1). Na bardzo wysoką wrażliwość $S$. sclerotiorum na prochloraz wskazywali wcześniej Gwiazdowski i Jajor (2005). W kombinacjach $\mathrm{z}$ zastosowaniem prochlorazu w stężeniach 5, 10 i $25 \mathrm{ppm}$, wszystkie izolaty $S$. sclerotiorum mieściły się w zakresach hamowania odpowiadających średnim procentom hamowania. W kombinacji $\mathrm{z}$ zastosowaniem prochlorazu w stężeniu 1 ppm, 34 izolaty mieściły się w zakresie odpowiadającym średniemu procentowi hamowania, a 24 izolaty wykazały większą wrażliwość na prochloraz w tym stężeniu (tab. 1, 2).

Tebukonazol wykazał zróżnicowany wpływ na hamowanie wzrostu kolonii grzybów w zależności od zastosowanego stężenia. Izolaty $S$. sclerotiorum były mało wrażliwe na dodatek $1 \mathrm{ppm}$ tebukonazolu w pożywce (29,8\%). Podwyższenie stężenia tej substancji czynnej do 5 ppm spowodowało wzrost efektywności hamowania do $75,7 \%$. Tebukonazol okazał się bardzo skuteczny w wyższych stężeniach - 10 i 25 ppm, ograniczając wzrost kolonii grzybów średnio o 95,8 i 100\% (tab. 1). Zastosowanie tebukonazolu przez innych autorów już w stężeniu 1 ppm wpłynęło na istotne inhibowanie wzrostu izolatów badanego gatunku (Gwiazdowski i Jajor 2005; Dalili i wsp. 2015). Prawie wszystkie izolaty $S$. sclerotiorum na pożywce $\mathrm{z}$ tebukonazolem w stężeniach 10 i 25 ppm oraz większość izolatów S. sclerotiorum (42) na pożywce z tebukonazolem w stężeniu 1 ppm, wykazały wrażliwość mieszczącą się w zakresach odpowiadających średnim procentom hamowania. W kombinacji z tebukonazolem w stężeniu 5 ppm tylko 32 izolaty mieściły się w zakresie odpowiadającym średniemu procentowi hamowania, a 26 izolatów wykazało słabszą wrażliwość na ten fungicyd w stężeniu 5 ppm (tab. 1, 2).

Izolaty $S$. sclerotiorum charakteryzowały się zróżnicowaną wrażliwością na tiofanat metylowy zależnie od użytego stężenia. Dodatek $1 \mathrm{ppm}$ tej substancji czynnej do pożywki spowodował zahamowanie wzrostu kolonii grzybów zaledwie o 7,7\%. Jednak podwyższenie stężenia do 5 ppm spowodowało znaczne zwiększenie efektywności w ograniczaniu średniego wzrostu kolonii grzybów do 61,3\%. Zastosowanie tiofanatu metylowego w dawce 10 i 25 ppm spowodowało skuteczne zahamowanie wzrostu kultur badanych izolatów odpowiednio o 91,0 i $98,8 \%$ (tab. 1). Skuteczność między innymi tiofanatu metylowego oraz tebukonazolu na ograniczenie wzrostu $S$. sclerotiorum w warunkach in vitro była przedmiotem badań innych autorów. Zahamowanie wzrostu kolonii S. sclerotiorum zostało stwierdzone przez Muellera i wsp. (2002) przy stężeniu $10 \mu \mathrm{g} / \mathrm{ml}$ tebukonazolu i stężeniu $50 \mu \mathrm{g} / \mathrm{ml}$ tiofanatu metylowego w pożywce. Wszystkie izolaty $S$. sclerotiorum rosnące na pożywce z tiofanatem metylowym w stężeniach 1 i 25 ppm oraz większość izolatów (53) rosnących na pożywce $z$ tiofanatem metylowym w stężeniu 10 ppm były wrażliwe na zastosowany fungicyd

Tabela 3. Procentowy udział izolatów wytwarzających sklerocja później niż izolaty kontrolne lub nie wytwarzających sklerocjów Table 3. The percentage of isolates that produce sclerotia later than the control isolates or do not produce sclerotia

\begin{tabular}{|c|c|c|c|c|c|c|c|c|c|}
\hline \multirow{2}{*}{$\begin{array}{l}\text { Fungicyd } \\
\text { Fungicide }\end{array}$} & \multirow{2}{*}{$\begin{array}{c}\text { Stężenie } \\
\text { Concentration } \\
{[\mathrm{ppm}]}\end{array}$} & \multicolumn{6}{|c|}{$\begin{array}{c}\text { Opóźnienie wytworzenia sklerocjów w stosunku do kontroli [dni] } \\
\text { Delay of sclerotia formation relative to control [days] }\end{array}$} & \multirow{2}{*}{$\begin{array}{c}\text { Brak } \\
\text { sklerocjów } \\
\text { Lack } \\
\text { of sclerotia }\end{array}$} & \multirow{2}{*}{$\begin{array}{c}\text { Suma } \\
\text { Amount }\end{array}$} \\
\hline & & 2 & 4 & 6 & 8 & 10 & 12 & & \\
\hline \multirow{4}{*}{ Azoxystrobin } & 1 & 13,3 & - & - & - & - & - & - & 13,3 \\
\hline & 5 & 45,0 & - & - & - & - & - & - & 45,0 \\
\hline & 10 & 63,3 & - & - & - & - & - & - & 63,3 \\
\hline & 25 & 86,7 & - & - & - & - & - & - & 86,7 \\
\hline \multirow{4}{*}{ Boscalid } & 1 & 55,0 & - & - & - & - & - & - & 55,0 \\
\hline & 5 & 55,0 & 38,3 & - & - & - & - & - & 93,3 \\
\hline & 10 & 16,7 & 35,0 & 20,0 & 10,0 & 5,0 & - & 6,7 & 93,4 \\
\hline & 25 & - & - & 11,7 & 3,3 & 23,3 & 8,3 & 45,0 & 91,6 \\
\hline \multirow{4}{*}{ Prochloraz } & 1 & 56,7 & 5,0 & - & - & - & - & - & 61,7 \\
\hline & 5 & 43,3 & 36,7 & 6,7 & - & - & - & - & 86,7 \\
\hline & 10 & 23,3 & 51,7 & 6,7 & 3,3 & - & - & - & 85,0 \\
\hline & 25 & - & 5,0 & - & 6,7 & 11,7 & - & 73,3 & 96,7 \\
\hline \multirow{4}{*}{ Tebuconazole } & 1 & 8,3 & - & - & - & - & - & - & 8,3 \\
\hline & 5 & 41,7 & - & - & - & - & - & - & 41,7 \\
\hline & 10 & 70,0 & 11,7 & - & - & - & - & - & 81,7 \\
\hline & 25 & 15,0 & 56,7 & 16,7 & 3,3 & - & - & - & 91,7 \\
\hline \multirow{4}{*}{ Tiophanate-methyl } & 1 & 8,3 & - & - & - & - & - & - & 8,3 \\
\hline & 5 & 40,0 & 8,3 & 5,0 & - & - & - & - & 53,3 \\
\hline & 10 & 10,0 & 5,0 & - & - & 3,3 & 1,7 & 76,7 & 96,7 \\
\hline & 25 & 1,7 & - & - & - & 1,7 & - & 96,7 & 100,0 \\
\hline
\end{tabular}


w danym stężeniu w zakresach odpowiadających średnim procentom hamowania. W kombinacji z zastosowaniem tiofanatu metylowego w stężeniu 5 ppm badane izolaty wykazały duże zróżnicowanie wrażliwości. Tylko 8 izolatów S. sclerotiorum charakteryzowało się wrażliwością w zakresie odpowiadającym średniemu procentowi hamowania, natomiast 32 izolaty przejawiały większą wrażliwość (tab. 1, 2).

Badania wykazały, że stopień wrażliwości izolatów na poszczególne fungicydy w danych stężeniach nie był związany $\mathrm{z}$ gatunkiem rośliny, z której izolowano patogena, jak również z miejscem oraz terminem poboru prób.

Wielkość inokulum, które stanowią pozostałe w glebie i na resztkach pożniwnych sklerocja, ma istotny wpływ na częstość występowania choroby w kolejnym sezonie wegetacyjnym (Boland i Hall 1988; Zhang i Xue 2010). Właściwe dobranie substancji czynnych w ochronie rzepaku w okresie kwitnienia pozwala na zredukowanie liczby tworzących się przetrwalników. Zmniejsza się w ten sposób ryzyko zakażenia roślin podatnych na tym stanowisku w następnych sezonach.

Użyte w badaniach substancje czynne przyczyniły się do opóźnienia wytwarzania sklerocjów przez kultury S. sclerotiorum. U 93,3\% izolatów kontrolnych sklerocja pojawiły się w szóstym dniu od momentu wyszczepienia na pożywkę PDA. Zastosowanie stężenia 1 ppm azoksystrobiny, tebukonazolu i tiofanatu metylowego nie spowodowało wyraźnego opóźnienia wytwarzania sklerocjów przez badane izolaty. U większości izolatów, sklerocja pojawiły się $\mathrm{w}$ tym samym czasie co w kontroli. Jedynie 8,3-13,3\% izolatów wytworzyło sklerocja dwa dni później. Użyte w badaniu boskalid i prochloraz w stężeniu 1 ppm wywołały niewielkie - dwudniowe opóźnienie pojawienia się sklerocjów u około połowy izolatów. Wprowadzenie do pożywki substancji czynnych w stężeniu 5 ppm spowodowało dwudniowe opóźnienie pojawienia się sklerocjów u 40-55\% izolatów. Część kultur
(8,3-38,3\%) wytworzyła sklerocja cztery dni później, a w przypadku tiofanatu metylowego oraz prochlorazu odpowiednio 5 i 6,7\% sześć dni później. Dodatek 10 ppm substancji czynnych wywołał bardzo zróżnicowaną reakcję badanych izolatów. Azoksystrobina i tebukonazol spowodowały opóźnienie pojawienia się sklerocjów do czterech dni u większości izolatów (odpowiednio 63,3 i 81,7\%). W przypadku boskalidu i prochlorazu opóźnienia następowały $\mathrm{w}$ różnym czasie i obejmowały dużą część izolatów, odpowiednio 93,4 i 85\%. Tiofanat metylowy w tym stężeniu całkowicie zahamował wytwarzanie sklerocjów u 76,7\% izolatów. Zastosowanie substancji czynnych w stężeniu 25 ppm było przyczyną ograniczenia powstawania przetrwalników u 86,7-100\% izolatów w różnym czasie. Azoksystrobina spowodowała opóźnienie pojawienia się sklerocjów o dwa dni, a tebukonazol maksymalnie o osiem dni. Dodatek pozostałych substancji czynnych w stężeniu 25 ppm skutkował całkowitym zahamowaniem wytwarzania przetrwalników u 45-96,7\% badanych izolatów (tab. 3).

\section{Wnioski / Conclusions}

1. Spośród zastosowanych w doświadczeniu substancji czynnych najsilniej wzrost kolonii $S$. sclerotiorum ograniczały prochloraz i tebukonazol.

2. Izolaty $S$. sclerotiorum charakteryzowały się niską wrażliwością na azoksystrobinę.

3. Zastosowane substancje czynne w niższych stężeniach: 1, 5 i 10 ppm nieznacznie opóźniły proces wytwarzania sklerocjów, z wyjątkiem tiofanatu metylowego w stężeniu $10 \mathrm{ppm}$.

4. Prochloraz i tiofanat metylowy w stężeniu $25 \mathrm{ppm}$ wpłynęły na całkowite zahamowanie wytwarzania sklerocjów u większości badanych izolatów.

\section{Literatura / References}

Boland G.J., Hall R. 1988. Relationships between the spatial pattern and number of apothecia of Sclerotinia sclerotiorum and stem rot of soybean. Plant Pathology 37 (3): 329-336.

Boland G.J., Hall R. 1994. Index of plant hosts of Sclerotinia sclerotiorum. Canadian Journal of Plant Pathology 16 (2): $93-108$.

Bolton M.D., Thomma B.P.H.J., Nelson B.D. 2006. Sclerotinia sclerotiorum (Lib.) de Bary: biology and molecular traits of a cosmopolitan pathogen. Molecular Plant Pathology 7 (1): 1-16.

Borecki Z. 1984. Fungicydy stosowane w ochronie roślin. PWN, Warszawa, 173 ss.

Dalili A., Bakhtiari S., Barari H., Aldaghi M. 2015. Effect of some fungicides against the growth inhibition of Sclerotinia sclerotiorum mycelial compatibility groups. Journal of Plant Protection Research 55 (4): 355-361.

Deising H.B., Reimann S., Pascholati S.F. 2008. Mechanisms and significance of fungicide resistance. Brazilian Journal of Microbiology 39 (2): 286-295.

Gwiazdowski R., Jajor E. 2005. Wrażliwość grzyba Sclerotinia sclerotiorum na wybrane substancje aktywne fungicydów. [The susceptibility of fungi Sclerotinia sclerotiorum to chosen active substances of fungicides]. Progress in Plant Protection/Postępy w Ochronie Roślin 45 (2): 701-704.

Gwiazdowski R., Korbas M. 2005. Integrowana ochrona przed agrofagami. s. 107-113. W: „Technologia produkcji rzepaku” (C. Muśnicki, I. Bartkowiak-Broda, M. Mrówczyński, red.). Wieś Jutra, Warszawa, 203 ss.

Jędryczka M. 2006. Epidemiologia i szkodliwość suchej zgnilizny kapustnych na rzepaku ozimym w Polsce. Rozprawy i Monografie. Instytut Genetyki Roślin Polskiej Akademii Nauk, Poznań, 150 pp.

Kaczmarek J., Brachaczek A., Jędryczka M. 2012. Zastosowanie testu płatkowego w badaniach odporności odmian rzepaku ozimego na zgniliznę twardzikową - wyniki doświadczeń łanowych. Rośliny Oleiste - Oilseed Crops 33 (2): 175-184.

Kapusta F. 2015. Ewolucja miejsca i roli rzepaku w rolnictwie oraz gospodarce Polski. Zeszyty Naukowe Szkoły Głównej Gospodarstwa Wiejskiego w Warszawie - Problemy Rolnictwa Światowego 15 (30), 2: 85-95.

Koch S., Dunker S., Kleinhenz B., Rohrig M., von Tiedemann A. 2007. Crop loss-related forecasting model for Sclerotinia stem rot in winter oilseed rape. Phytopathology 97 (9): 1186-1194. 
Korbas M., Horoszkiewicz-Janka J., Jajor E. 2008. Uproszczone systemy uprawy a występowanie sprawców chorób. [Simplified systems of soil management in relation to the occurrence of disease casual agents]. Progress in Plant Protection/Postępy w Ochronie Roślin 48 (4): 1431-1438.

Li G.Q., Huang H.C., Miao H.J., Erickson R.S., Jiang D.H., Xiao Y.N. 2006. Biological control of sclerotinia diseases of rapeseed by aerial applications of the mycoparasite Coniothyrium minitans. European Journal of Plant Pathology 114 (4): 345-355.

Liu X., Yin Y., Yan L., Michailides T.J., Ma Z. 2009. Sensitivity to iprodione and boscalid of Sclerotinia sclerotiorum isolates collected from rapeseed in China. Pesticide Biochemistry and Physiology 95 (2): 106-112.

Ma H.X., Chen Y., Wang J.X., Yu W.Y., Tang Z.H., Chen C.J., Zhou M.G. 2009. Activity of carbendazim, dimethachlon, iprodione, procymidone and boscalid against Sclerotinia stem rot in Jinagsu Province of China. Phytoparasitica 37 (5): $421-429$.

Ma Z., Michailides T.J. 2005. Advances in understanding molecular mechanisms of fungicide resistance and molecular diagnosis of resistant genotypes of phytopathogenic fungi. Crop Protection 24 (10): 853-863.

Matheron M.E., Porchas M. 2004. Activity of boscalid, fenhexamid, fluazinam, fludioxonil, and vinclozolin on growth of Sclerotinia minor and S. sclerotiorum and development of lettuce drop. Plant Disease 88 (6): 665-668.

Mueller D.S., Dorrance A.E., Derksen R.C., Ozkan E., Kurle J.E., Grau C.R., Gaska J.M., Hartman G.L., Bradley C.A., Pedersen W.L. 2002. Efficacy of fungicides on Sclerotinia sclerotiorum and their potential for control of Sclerotinia stem rot on soybean. Plant Disease 86 (1): 26-31.

Paul V.P. 1988. Krankheiten und Schädlinge des Rapses. Verlag Th. Mann, Gelsenkirchen-Bauer, 121 pp.

Rudko T. 2011. Uprawa rzepaku ozimego. Poradnik dla producentów. Wydawnictwo Instytutu Agrofizyki im. Bohdana Dobrzańskiego Polskiej Akademii Nauk, Lublin, 78 pp.

Stammler G., Benzinger G., Speakman J. 2007. A rapid and reliable method for monitoring the sensitivity of Sclerotinia sclerotiorum to boscalid. Journal of Phytopathology 155 (11-12): 746-748.

Starzycki M., Starzycka E. 1999. Badania nad odpornością rzepaku na Sclerotinia sclerotiorum (Lib.) de Bary w Polsce i na świecie. Rośliny Oleiste - Oilseed Crops 20 (1): 51-58.

Wang J.X., Ma H.X., Chen Y., Zhu X.F., Yu W.Y., Tang Z.H., Chen C.J., Zhou M.G. 2009. Sensitivity of Sclerotinia sclerotiorum to boscalid in Jiangsu Province of China. Crop Protection 28 (10): 882-886.

Xu T., Wang Y.T., Liang W.S., Yao F., Li Y.H., Li D.R., Wang H., Wang Z.Y. 2013. Involvement of alternative oxidase in the regulation of sensitivity of Sclerotinia sclerotiorum to the fungicides azoxystrobin and procymidone. Journal of Microbiology $51(3): 352-358$.

Zhang J.X., Xue A.G. 2010. Biocontrol of Sclerotinia stem rot (Sclerotinia sclerotiorum) of soybean using novel Bacillus subtilis strain SB24 under control conditions. Plant Pathology 59 (2): 382-391. 